\title{
Characterization of the surface and mechanical behavior of polyurethane microporous films doped with silver nanoparticles
}

\author{
Liana Cătălina Ciobanu,,$^{1^{*}}$ Constantin Ciobanu ${ }^{2}$ \\ $1^{*}$ Faculty of Physics, "Al.I.Cuza" University, Bd. Carol I no.11, lasi, Romania; fax: \\ +40232 201150, e-mail: ciobanulcatalina@gmail.com \\ 2 Institute of Macromolecular Chemistry "P.Poni", Aleea Gr. Ghica Vodă 41 A, lasi, \\ Romania; fax: +40232 211299.
}

(Received: 13 June, 2008; published: 02 August, 2009)

\begin{abstract}
The aim of this study was to investigate the effects of silver nanoparticles (Ag-NPs) concentration on surface of polyurethane microporous films. The Ag-NPs have a diameter between 1.74-10 nm and were synthesized in the polymer matrix. The effects of Ag-NPs at the surface of polyurethane (PU) microporous films were investigated by means of attenuated total reflection Fourier infrared (ATR-FTIR) spectroscopy, atomic force microscopy (AFM) and contact angle measurements. The mechanical behavior of $\mathrm{PU}$ films vs Ag-NPs concentration was also studied. The Ag-NPs induce changes in the PU surface structure, wettability properties, topography and mechanical properties. These phenomena may be due to interactions between Ag-NPs and urethane groups which form new structure urethane-silver-urethane with a specific morphology and the nanostructuring of the surface by means of metallic nanoparticles.
\end{abstract}

\section{Introduction}

Polyurethanes represent a wide class of polymers with multiple applications like foams, rubbers, synthetic leather, coatings, fibers and biomaterials [1-3]. These multiple applications are due to their excellent chemical resistance, good resistance to ozone and oxygen, high tensile, shear strength, high elasticity and flexibility, good biocompatibility. Also, the PU can be made in a variety of forms like film, foam, hydrogel, hydrocolloid and with different properties by varying the type of monomers and adding other compounds.

Silver is one of the non toxic metals used in nanoparticles or ionic form with different materials due to its good antimicrobial properties [4]. Thus silver nanoparticles are used in combination with antibiotics to enhance antibacterial effect [5], in textile fiber to prevent odour or infection with pathogenic bacteria [6,7], to coat PU foams for antibacterial water filter [8] or facemasks to protect against infectious agents [9]. The antibacterial effects of Ag-NPs depend on the total surface area of the nanoparticles. Smaller particles $(<10 \mathrm{~nm})$ have a larger surface to volume ratio and are more efficient for antibacterial activity. Also the Ag-NPs have an enhaced antibacterial effect at low concentrations. For example a concentration below $8 \mu \mathrm{g} \mathrm{Ag-NPs} / \mathrm{cm}^{2}$ at the surface is sufficient to be completely cytotoxic to Escherichia coli [10].

Ag-NPs synthesized in the polymer matrix produce changes in the polymer surface structure and therefore in surface properties. The mechanical behavior of polymer is 
also changed [11]. For materials used in biomedical application surface properties are very important because the surface is in contact with the living tissue. For this reason, in this paper we studied the influence of the Ag-NPs over the PU surface structure and properties. Also, we analyzed the mechanical behavior of the PU microporous films vs. Ag-NPs concentration.

\section{Results and discussion}

\section{ATR-FTIR spectra}

The surface of PU samples with different Ag-NPs concentrations (a control sample without $\mathrm{Ag}(\mathrm{M})$ and samples with concentrations of $9.71\left(\mathrm{P}_{1}\right), 44.68\left(\mathrm{P}_{2}\right), 69.11\left(\mathrm{P}_{3}\right)$ and $97.28\left(\mathrm{P}_{4}\right)$ ppm Ag-NPs, respectively) was characterized using ATR-FTIR spectroscopy. The characteristic bands for the $M$ and $P_{1}-P_{4}$ samples for the range $3450-700 \mathrm{~cm}^{-1}$, are shown in Figure 1. One may observe from the Figure 1 that there are no new bands, nor some significant displacements of the peaks, due to the nanometric Ag in different concentrations.

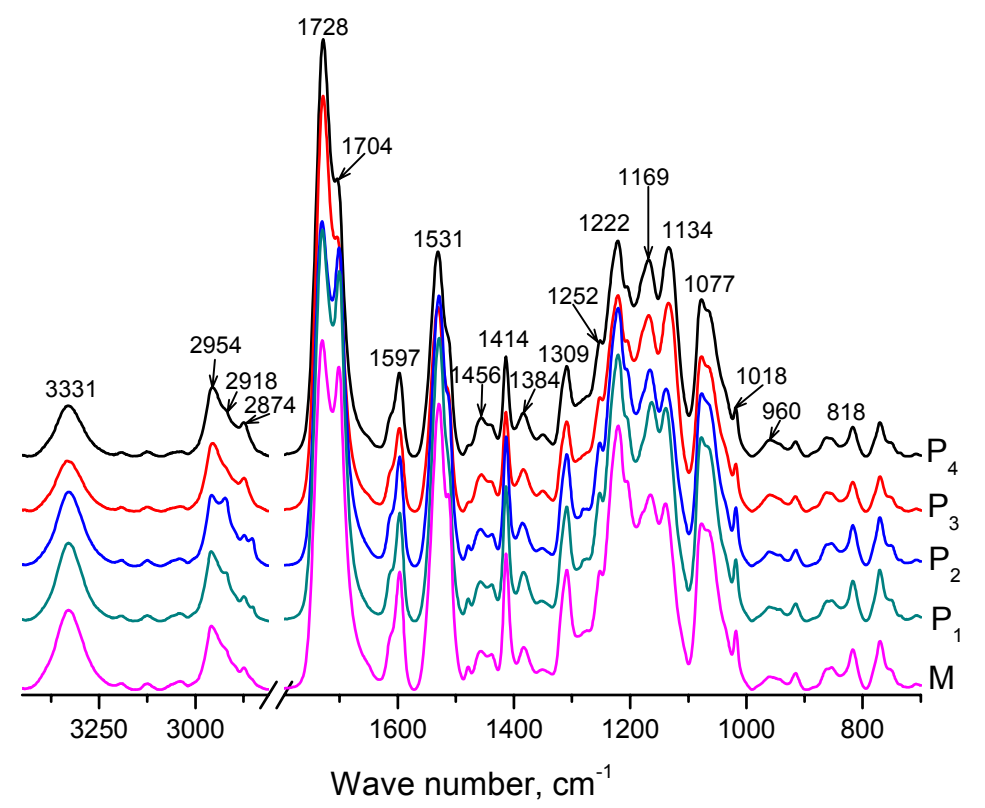

Fig. 1. ATR-FTIR spectra of PU sample M, $P 1$ - P4 between $3450-700 \mathrm{~cm}^{-1}$.

However, there are changes of the spectral band surfaces. Thus, the area of the stretch vibration band of the bonded $\mathrm{NH}$ group, $v(\mathrm{NO}-\mathrm{H})$, from $3331 \mathrm{~cm}^{-1}$ decreases, while the area of the stretch vibration band $v\left(\mathrm{CH}_{2}\right)$, in the range $3010-2820 \mathrm{~cm}^{-1}$, increases with the increase of the Ag-NPs concentration (Figure 2); this phenomenon was also observed in the case of another metal [12]. One may also observe changes in the ratio of the bands specific for the carbonyl group in the range $1770-1640 \mathrm{~cm}^{-1}$. As the Ag-NPs concentration in the PU matrix increases, the stretch band at 1704 $\mathrm{cm}^{-1}$, specific for $\mathrm{CO}$ from the urethane groups associated through hydrogen bonds in hard domains, decreases, while band at $1728 \mathrm{~cm}^{-1}$, specific for $\mathrm{CO}$ in the free, disordered urethane groups, increases [13-15]. 


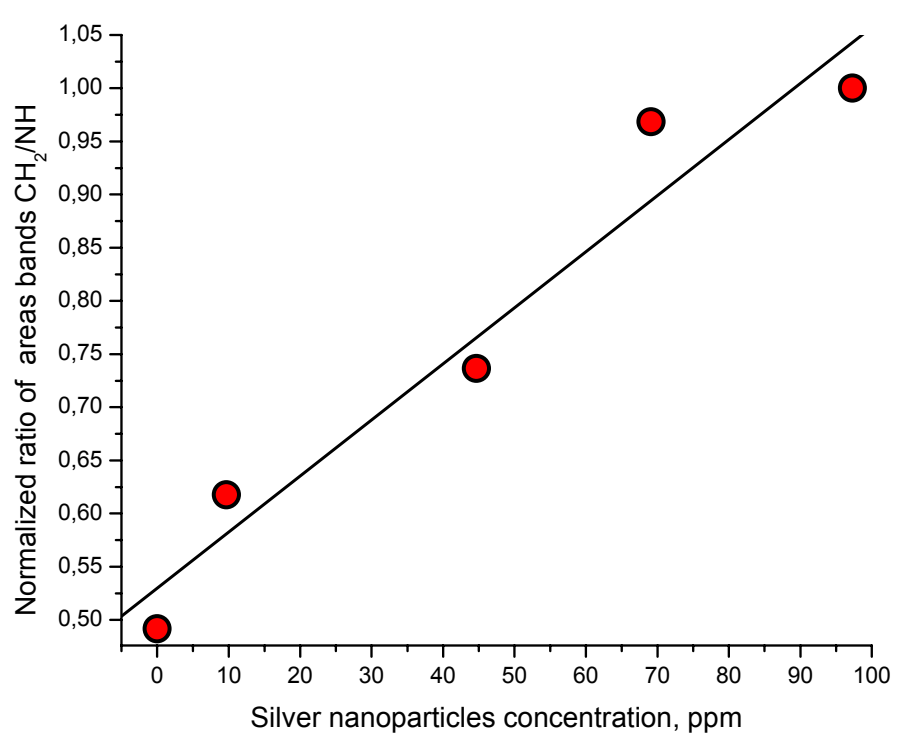

Fig. 2. Modifications of normalized ratio between areas of the stretch vibration bands of $\mathrm{CH}_{2}\left(2820-3010 \mathrm{~cm}^{-1}\right)$ and $\mathrm{NH}\left(3235-3420 \mathrm{~cm}^{-1}\right)$ vs. Ag-NPs concentration.

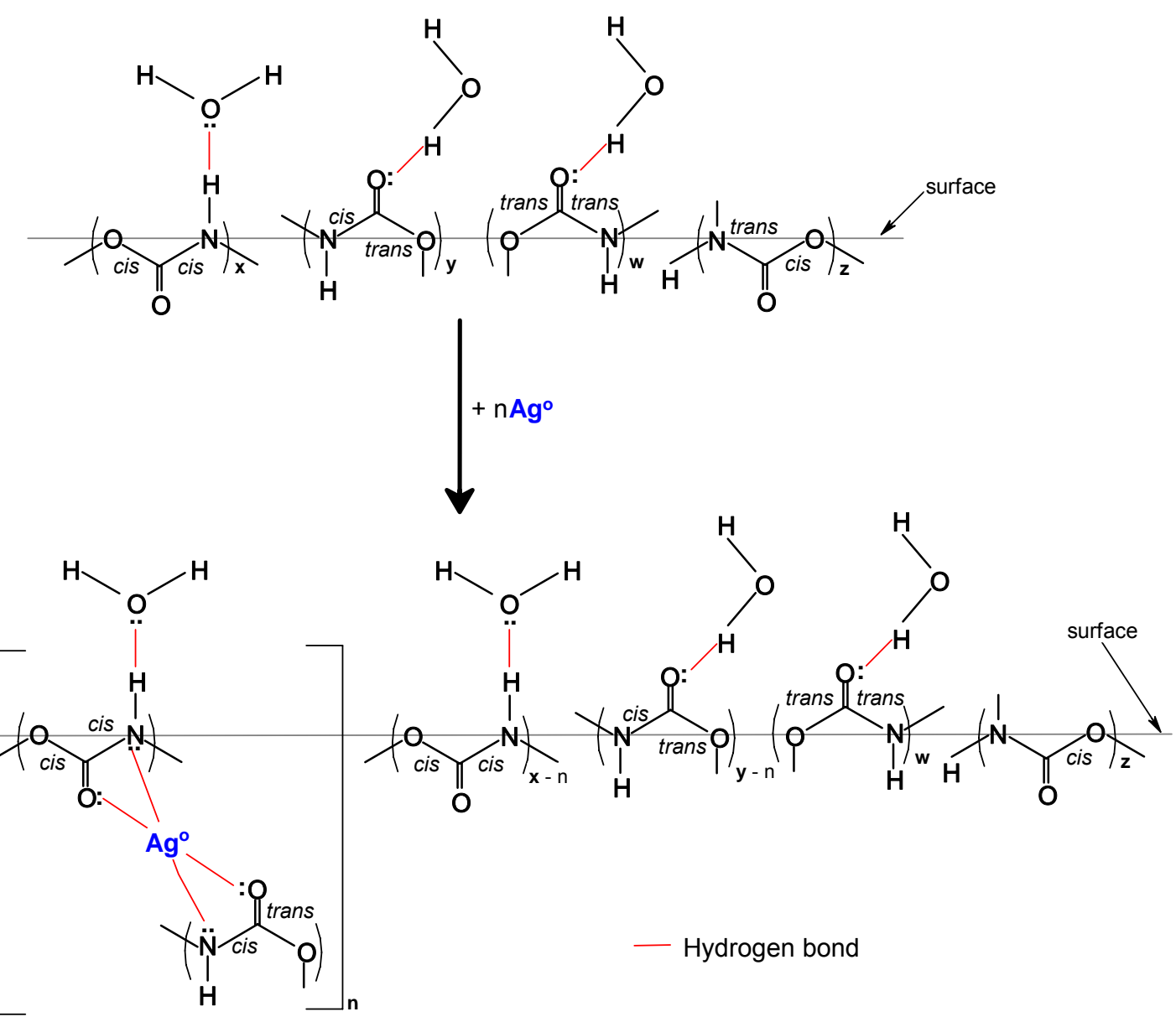

Fig. 3. The steric conformation change for the urethane groups at the PU surface, due to their interaction with $\mathrm{Ag}^{0}$. 
The same phenomenon is observed in the bands $v_{\text {sim }}(\mathrm{C}-\mathrm{O}-\mathrm{C})$, associated with the urethane structure placed upon the ester ones, where the absorption band at 1134 $\mathrm{cm}^{-1}$ increases, while that band at $1169 \mathrm{~cm}^{-1}$ decreases with the increase of the AgNPs concentration. The weak band at $1018 \mathrm{~cm}^{-1}$, characteristic for $v_{\text {sim }}(\mathrm{C}-\mathrm{O}-\mathrm{C})$, associated with the ester structure, becomes a very weak shoulder for the samples $\mathrm{P}_{3}$ and $\mathrm{P}_{4}$ (Figure 1).

The above mentioned phenomena might be explained if we consider that the urethane group has four different steric conformations: cis-cis, trans-trans, cis-trans and trans-cis [16]. Thus, at the surface of the polyurethane matrix, one may have these conformations in different molar ratios. By introducing the nanometric silver into $\mathrm{PU}$, new urethane-Ag-urethane structures will be formed at its surface, which modify the molar ratio and the steric conformation of the urethane structures (Figure 3).

This might be possible because the zero valence Ag may react with the $\mathrm{p}$ electrons of the nitrogen and oxygen from the urethane structure (-HN-CO-O-) as one has observed in the case of the polyvinyl pyrrolidone where $\mathrm{Ag}^{0}$ forms associations with the $\mathrm{p}$ electrons of the $=\mathrm{N}-\mathrm{CO}$ - structure [17].

\section{AFM Studies}

The topography and roughness of the PU surface were studied by AFM. The AFM $z(x, y)$ images were used in order to estimate the root mean square roughness, $R_{r m s}$. The root mean square roughness of the surface was calculated according to the formula:

$R_{r m s}=\sqrt{\frac{\sum_{n=1}^{N}\left(z_{n}-\mu\right)^{2}}{N}}$

where: $\mathrm{N}$ - the number of data points of the image; $\mathrm{z}_{\mathrm{n}}$ - height data of the $\mathrm{n}$-th point; $\mu$ - average height.

The root mean square roughness of the PU surface, $R_{r m s}$, decreases with the increase of the concentration of Ag-NPs, which shows that the Ag-NPs presence into the polymer matrix has the effect of smoothing the PU samples surface (Table 1). The roughness reduction according to the increase of the Ag-NPs concentration is attributed to the modification of the urethane clusters morphology, passing from the cylindrical and spherical geometry [14] to plane structures, where the urethane groups react with the Ag-NPs, leading to plane organized forms [13].

Tab. 1. The root mean square roughness, $R_{r m s}$, of the PU samples.

\begin{tabular}{cccccc}
\hline Sample & $\mathrm{M}$ & $\mathrm{P}_{1}$ & $\mathrm{P}_{2}$ & $\mathrm{P}_{3}$ & $\mathrm{P}_{4}$ \\
\hline $\begin{array}{c}\mathrm{R}_{\mathrm{rms}} \\
(\mathrm{nm})\end{array}$ & 104.65 & 103.65 & 85.70 & 75.21 & 62.36 \\
\hline
\end{tabular}

$\mathrm{Ag}^{0}$ has a contribution to the modification of the surface topography. This phenomenon is very well emphasized from the AFM images in the surface topography (Figure 4). One may also notice the micropores at the PU surface, for all the samples in Figure 4. 


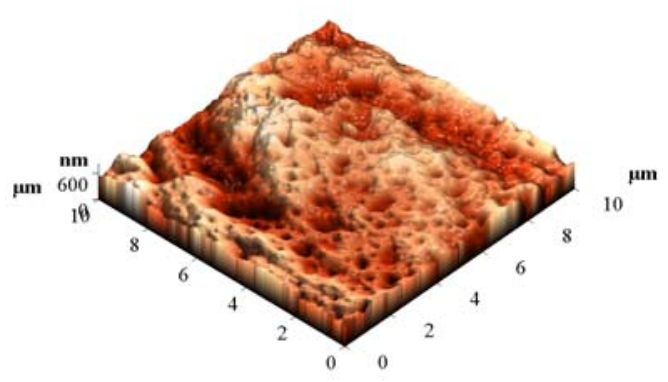

(a)

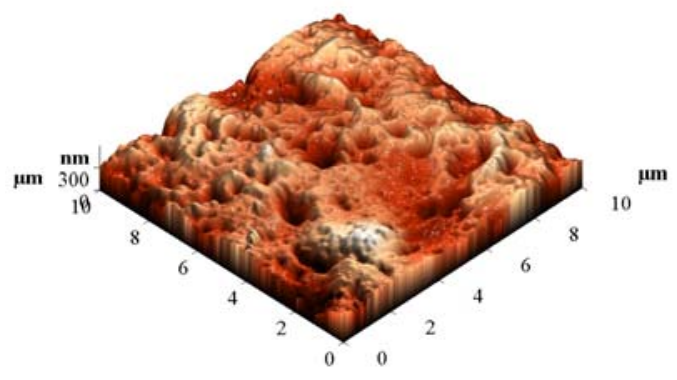

(c)

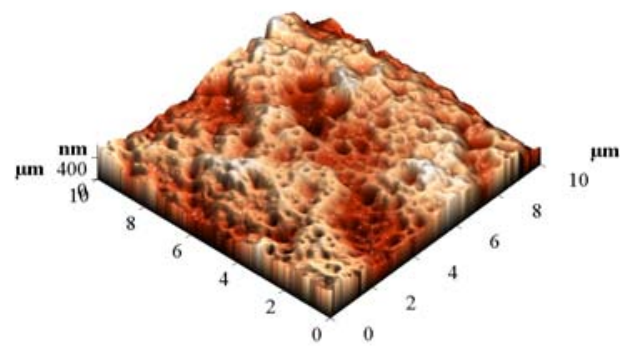

(b)

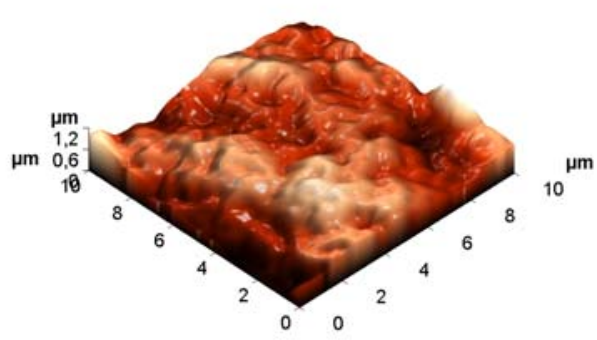

(d)

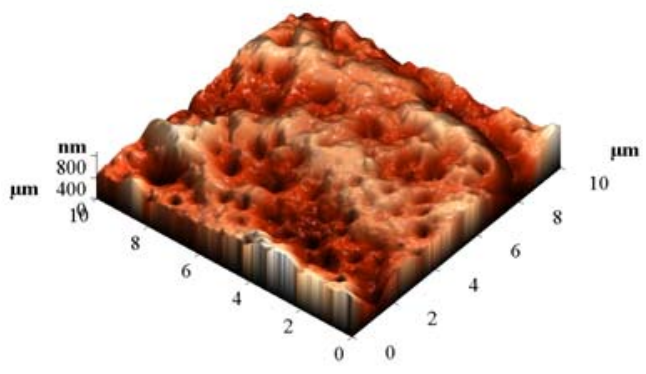

(e)

Fig. 4. AFM images of microporous surface $P U:$ a) $M ; b) P_{1}$; c) $P_{2}$; d) $P_{3} ;$ e) $P_{4}$.

Static contact angle and surface energy of $P U$

The PU surface wettability was evaluated by measuring the static contact angle (sesile drop method) of the bidistilled and deionized water on the surface. As liquids for the calculation of the PU surface energy, we used bidistilled and deionized water and pure ethylene glycol. The surface energetic characteristics of the liquids used for measurement are presented in Table 2. The relation between the contact angle and the interfacial tension solid-liquid $\gamma_{S L}$, liquid-vapors $\gamma_{L V}$ and solid-vapors $\gamma_{S V}$, is given by Young equation [18]:

$\gamma_{L V} \cos \theta=\gamma_{S V}-\gamma_{S L}$ 
One may separate $\gamma_{L V}$ and $\gamma_{S V}$ into two interaction components: a disperse one, $\gamma_{L V}^{d}$, $\gamma_{S V}^{d}$ representing the van der Waals interactions, and the polar one, $\gamma_{L V}^{p}, \gamma_{S V}^{p}$, representing the polar interactions between the dipoles of the molecules of the two mediums in contact. The interfacial solid-liquid tension may be obtained from the equation [19]:

$\gamma_{S L}=\gamma_{S V}+\gamma_{L V}-2\left(\sqrt{\gamma_{S V}^{\mathrm{p}} \gamma_{L V}^{p}}+\sqrt{\gamma_{S V}^{d} \gamma_{L V}^{d}}\right)$

From the equations (2) and (3) results:

$\gamma_{L V}(1+\cos \theta)=2 \sqrt{\gamma_{S V}^{p} \gamma_{L V}^{p}}+2 \sqrt{\gamma_{S V}^{d} \gamma_{L V}^{d}}$

The surface energy is sum of its components:

$\gamma_{S V}=\gamma_{S V}^{p}+\gamma_{S V}^{d}$

The PU surface energy $\gamma_{S V}$ and its components (polar $\gamma_{S V}^{p}$ and disperse $\gamma_{S V}^{d}$ ) have been determined from the equations (4) and (5), using the values of the contact angle measured for two different liquids.

The values of the contact angle of the water with the PU surface and the PU surface energy are shown in Table 3.

Tab. 2. Components of the surface energy of the liquids used for testing the polymer surface and interface properties [20].

\begin{tabular}{cccc}
\hline Liquid & $\gamma_{L V}^{p}(\mathrm{mN} / \mathrm{m})$ & $\gamma_{L V}^{d}(\mathrm{mN} / \mathrm{m})$ & $\gamma_{L V}(\mathrm{mN} / \mathrm{m})$ \\
\hline Water & 51 & 21.8 & 72.8 \\
Ethylene glycol & 19 & 29 & 48 \\
\hline
\end{tabular}

Tab. 3. Water contact angle $\theta$ and surface energy $\gamma_{S V}$ (polar component $\gamma_{S V}^{p}$, disperse component $\gamma_{S V}^{d}$ ) of PU.

\begin{tabular}{ccccc}
\hline Sample & $\theta\left(^{\circ}\right)$ & $\gamma_{S V}^{p}(\mathrm{mN} / \mathrm{m})$ & $\gamma_{S V}^{d}(\mathrm{mN} / \mathrm{m})$ & $\gamma_{S V}(\mathrm{mN} / \mathrm{m})$ \\
\hline $\mathrm{M}$ & 71.61 & 25.56 & 6.39 & 31.95 \\
$\mathrm{P}_{1}$ & 70.75 & 22.95 & 9.28 & 32.23 \\
$\mathrm{P}_{2}$ & 54.61 & 42.06 & 5.75 & 47.81 \\
$\mathrm{P}_{3}$ & 73.50 & 24.17 & 6.23 & 30.40 \\
$\mathrm{P}_{4}$ & 84.40 & 19.72 & 21.32 & 41.04 \\
\hline
\end{tabular}

From Table 3 one may notice that the water contact angle decreases at $M, P_{1}$ and $P_{2}$, while it begins to grow with $P_{3}$, arriving at $P_{4}$ to be almost $13^{\circ}$ bigger than $M$. Thus, for the samples $M, P_{1}$ and $P_{2}$ the surface wettability increases, while for the samples $\mathrm{P}_{3}, \mathrm{P}_{4}$ it decreases with the increasing of Ag-NPs concentration. This might be explained considering that Ag-NPs, for concentrations below 45 ppm, is reacting first with urethane structures bonded to the ester chain, which are not organized in clusters. Generally, these are forming hydrogen bonds with -COO- groups from the ester chain and may react easier with Ag-NPs, forming urethane-Ag structures, which enrich the $\mathrm{PU}$ surface with $\mathrm{C}=\mathrm{O}$ groups, capable to form hydrogen bonds with the water. As the Ag-NPs concentration grows, the -NHCOO- groups start to consume in 
the arranged clusters urethane-urethane, forming the urethane-Ag-urethane structures; these structures lead to the reduction of the molar concentration of the polar $\mathrm{C}=\mathrm{O}$ groups on the $\mathrm{PU}$ surface, together with the increase of its hydrophobic behavior and thus, the increase of the contact angle with the water.

The surface energy $\gamma_{S V}$ is generally bigger for the $\mathrm{P}_{1}-\mathrm{P}_{4}$ samples, in comparison with $M$. Thus, for the $P_{2}$ and $P_{4}$ samples, the surface energy is $15.86,10.09 \mathrm{mN} / \mathrm{m}$ respectively bigger than for $M$. Meanwhile, the dispersed surface energy compound $\gamma_{S V}^{d}$, given by the Van der Waals forces and the induced dipoles, increases at $\mathrm{P}_{4}$ with $14.93 \mathrm{mN} / \mathrm{m}$ in comparison with $\mathrm{M}$, and it overtakes the polar compound $\gamma_{S V}^{p}$ with $1.6 \mathrm{mN} / \mathrm{m}$. These results might suggest that Ag-NPs increase the surface energy of the polyurethane, while the urethane-Ag-urethane structures are more hydrophobic, and easily form induced dipoles.

\section{Mechanical analysis}

By analyzing the stress-strain curves $(\sigma-\varepsilon)$ in the elastic domain $(0.1-2 \%$ elongation) for the $\mathrm{M}$ and $\mathrm{P}_{1}-\mathrm{P}_{4}$ samples, one may notice a change of these, according to the Ag-NPs concentration in the PU matrix. Thus, the PU material's capacity of absorbing internal work in the volume unity in the elastic domain (elastic resilience $U_{e}$ ) decreases when Ag-NPs concentration increase (with 68\% at the $\mathrm{P}_{4}$ than M). Also, as the Ag-NPs concentration grows, the PU material becomes softer, the initial elasticity module $\left(E_{i}\right)$ decreases becoming $68 \%$ low at the $\mathrm{P}_{4}$ than $\mathrm{M}$ (Table 4). These results suggest that Ag-NPs interact with the PU macromolecules to form new structures, with weaker inter- and intramolecular bonds.

The initial elasticity module $\left(E_{i}\right)$ was obtained from the equation [21]:

$$
E_{i}=\frac{\sigma_{e}}{\varepsilon}
$$

where: $\sigma_{e}-$ stress; $\varepsilon$ - strain.

The elastic resilience $\left(U_{e}\right)$ was obtained from the equation:

$$
U_{e}=\sigma_{e} \cdot \ln (1+\varepsilon)
$$

Tab. 4. Elastic resilience $\left(U_{e}\right)$ and initial elasticity module $\left(E_{i}\right)$ of the PU films.

\begin{tabular}{ccc}
\hline Sample & $\begin{array}{c}\text { Elastic resilience } \\
\left(\mathrm{U}_{\mathrm{e}}\right), \mathrm{MPa}\end{array}$ & $\begin{array}{c}\text { Initial elasticity module } \\
\left(\mathrm{E}_{\mathrm{i}}\right), \mathrm{MPa}\end{array}$ \\
\hline $\mathrm{M}$ & 1.50 & 23.79 \\
$\mathrm{P}_{1}$ & 1.10 & 16.83 \\
$\mathrm{P}_{2}$ & 1.04 & 9.76 \\
$\mathrm{P}_{3}$ & 0.74 & 9.00 \\
$\mathrm{P}_{4}$ & 0.64 & 7.63 \\
\hline
\end{tabular}

\section{Conclusions}

The Ag-NPs have a dramatic action upon the polyurethane structure, as they interact with the -NHCOO- groups bonded to the ester chain, and from the regular urethaneurethane clusters, forming new structures Ag-urethane and urethane-Ag-urethane, 
thus modifying the morphology, wettability, surface energy and the topography of the polyurethane matrix surface.

Ag-NPs modify the polyurethane matrix, determining it to absorb a smaller amount of mechanical work. Thus, both the elastic resilience and the initial module becomes smaller, and the polymer becomes softer and less tough.

\section{Experimental part}

\section{Materials and samples preparation}

The polyurethane (PU) was synthesized from poly(ethylene adipate)diol (PEA) with a molecular mass of $2000 \mathrm{Da}$, the hydroxyl number $56 \mathrm{mg} \mathrm{KOH} / \mathrm{g}$, the acidity number $0.2 \mathrm{mg} \mathrm{KOH} / \mathrm{g}, 4.4$ '-diisocyanate of diphenyl methane (MDI), freshly distilled, with a concentration in isocyanate of 99.96\%, 1,4-buthane diol (BD)> 99\% (Sigma-Aldrich) anhydrous and dimethylformamide (DMF) $>99.8 \%$ anhydrous (Sigma -Aldrich). The synthesis was performed through the prepolymer procedure at $60^{\circ} \mathrm{C}$, according to a previous method [22]. The molar ratio between the compounds is PEA:MDI:BG = $1: 6: 5$, the concentration of the solution PU-DMF is $35 \%$ dry substance, the viscosity is $80,000 \mathrm{cP}$ at $20^{\circ} \mathrm{C}$ (by the Brookfield viscosimeter, rotor number 4). The molar mass for PU was 112,000 Da (gel chromatography). Elements analysis: calculated $\mathrm{C}$ $60.53 \%, \mathrm{H} 8.49 \%$, N 4.33\%; found: C 60.18\%, 60.45\%; H 8.37\%, 8.46\%; N 4.55\%, $4.61 \%$. The general structure of the PU is shown in Scheme 1.

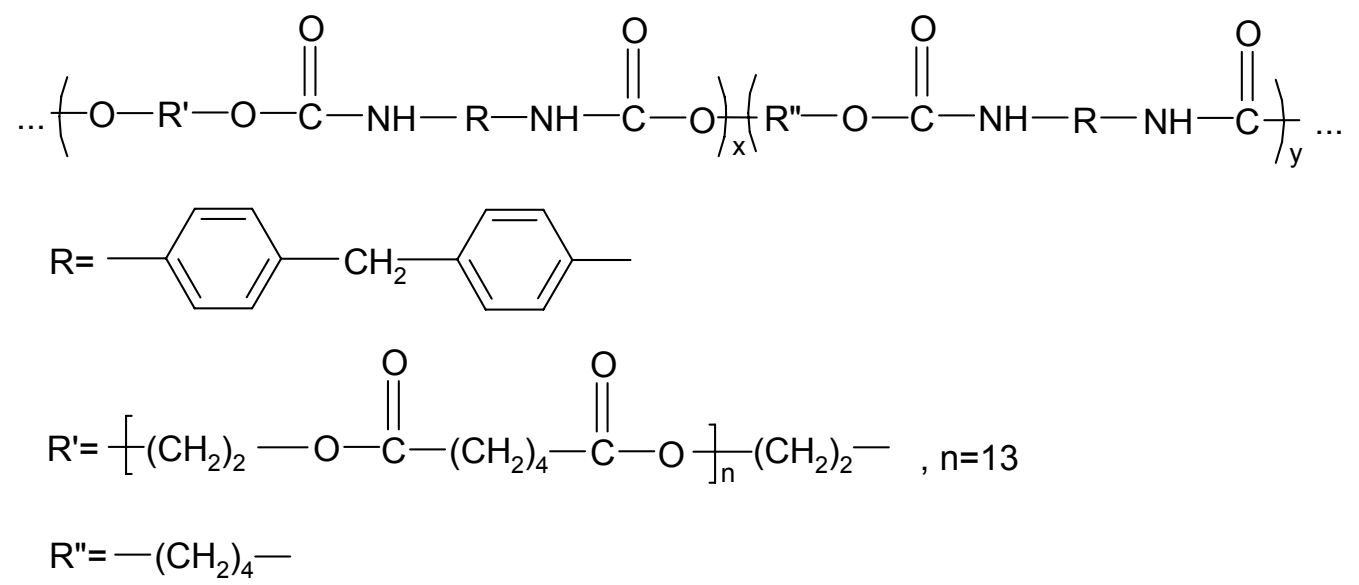

Molar ratio x:y 1:5 (H-NMR); Moles urethane/1000 $\mathrm{g}=3.27$.

Scheme 1. The PU molecular structure.

The Ag-NPs were synthesized with sodium borohydrate, in the polymer matrix, according to a known method [23]. The diameter of the nanoparticles was estimated with a Zetasizer device. From the histogram obtained with the Zetasizer device (Figure 5) [13], one can observe that the nanoparticles have a diameter between 1.74-10 $\mathrm{nm}$. The biggest part of the nanoparticles has a diameter between $4-5 \mathrm{~nm}$.

The Ag-NPs concentration in PU was determined by UV-VIS spectroscopy in DMF solution, from a etalon curve. We used a Spectrophotometer of 6505 UV/VIS type (made in England), with computerized data processing.

The microporous films of $\mathrm{PU}$ and $\mathrm{PU}-\mathrm{Ag}^{\circ}$ were realized through phase inversion in distilled and deionized water at $45^{\circ} \mathrm{C}$, according to the previous data $[22,24]$. 
We realized five types of microporous films: a control sample without $\mathrm{Ag}(\mathrm{M})$ and samples with concentrations of $9.71\left(\mathrm{P}_{1}\right), 44.68\left(\mathrm{P}_{2}\right), 69.11\left(\mathrm{P}_{3}\right)$ and $97.28\left(\mathrm{P}_{4}\right) \mathrm{ppm}$ Ag-NPs, respectively. Ag-NPs concentration is the same in bulk and in the interfacial layer, certified by the ATR FTIR spectra which are the same at surface and in transversal section of PU film.

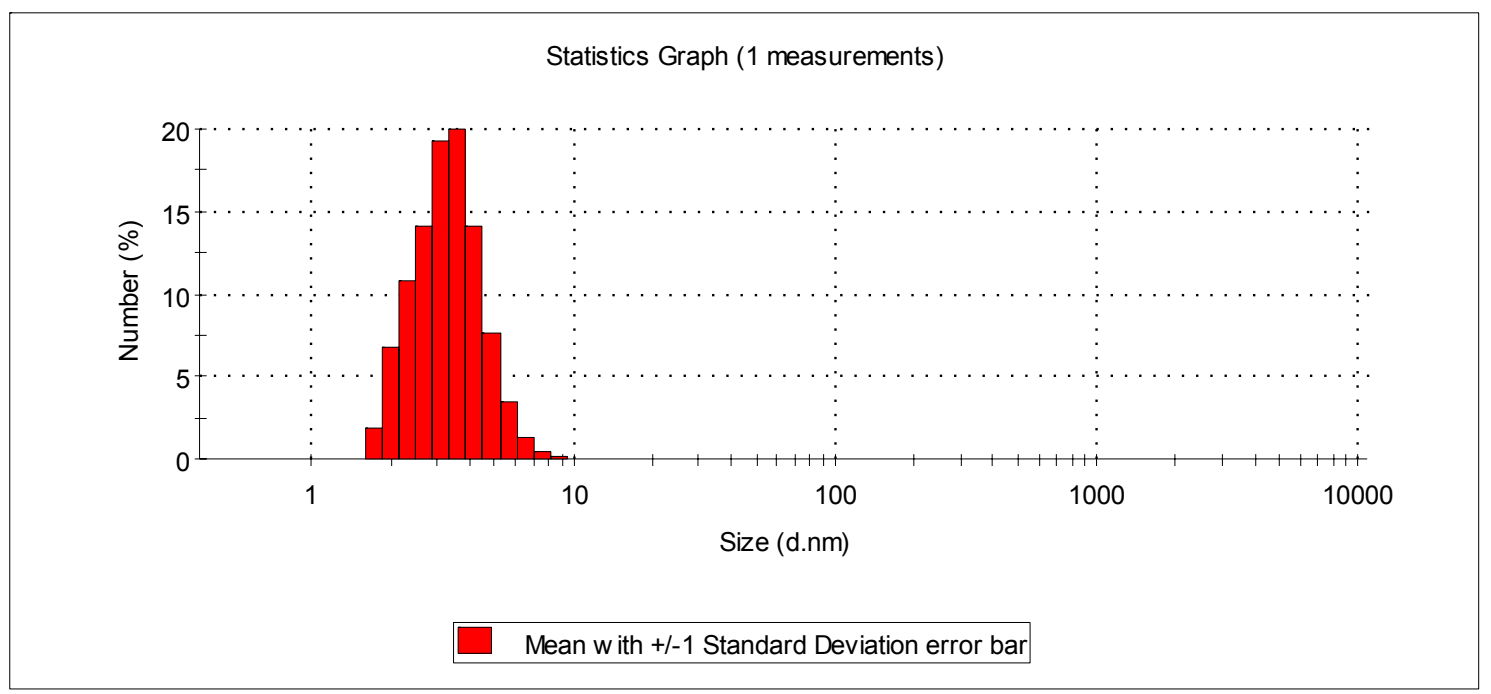

Fig. 5. Granulometric distribution of Ag-NPs in the PU matrix.

\section{Measurements}

ATR-FTIR analysis were done using a Bruker Vertex 70 (U.S.) apparatus, having a diamond crystal with $6 \mathrm{~mm}^{2}$ of surface. The samples' surface was scanned by an optical radiation in the range of $600-4000 \mathrm{~cm}^{-1}$, under an incidence angle of $45^{\circ}$.

The AFM measurements were carried in the half-contact mode on a SPM Solver PRO-M Russia device, with a cantilever NSG10, at the room temperature $25^{\circ} \mathrm{C}$ and at normal atmospheric pressure. The cantilever is rectangular, with a peak height of $10-15 \mu \mathrm{m}$, curvature radius of $10 \mathrm{~nm}$ and the cone angle $\mathrm{j} \leq 22^{\circ}$. The topography and phase were simultaneously registered for each sample on surfaces of $10 \mu \mathrm{m} \times 10$ $\mu \mathrm{m}$. The AFM measurements were repeated for different places on the samples, in order to verify the results reproducibility.

The static contact angle measurements were performed through the sessile drop method, with an apparatus KSV CAM 101 (KSV Instruments, Helsinki, Finland). The values of the static contact angle presented were the average of minimum ten measured values obtained on the image of liquid drop profile, for $1 \pm 0.1 \mu$ drop size. The maximum error in the contact angle measuring was under $3 \%$.

The mechanical tests were performed on a TIRA test 2161 apparatus (Germany). The sample was strained at the room temperature $25^{\circ} \mathrm{C}$, with a speed of $10 \mathrm{~mm} / \mathrm{min}$.

\section{References}

[1] Wang, M. Y.; Hsien, C.-H. U.S. Patent 54748101995.

[2] Rudd, G.E.; Handbook of Plastics, Elastomers, and Composites, Harper, C.A., Ed., McGraw Hill, New York 1992.

[3] Vermette, P.; Griesser, H.J.; Laroche, G.; Guidoin, R. Biomedical Applications of Polyurethanes, Eurekah Pubmed, 2001. 
[4] Babu, R.; Zhang, J.; Beckman, E.J.; Virji, M.; Pasculle, W. A., Wells, A. Biomaterials 2006, 27, 4304.

[5] Li, P.; Li, J.; Wu, C.; Wu, Q.; Li, J. Nanotechnology 2005, 16, 1912.

[6] kulpinski, P. e-polymers 2007, no. 068.

[7] Durán, N.; Marcato, P. D.; De Souza, G. I. H.; Alves, O. L.; Esposito, E. J. Biomed. Nanotechnol. 2007, 3, 203

[8] Prashant, J.; Pradeep, T. Biotechnol. Bioeng. 2005, 90, 59.

[9] Li, Y.; Leung, P.; Yao, L.; Song, Q. W.; Newton, E. J. Hosp. Infec. 2006, 62, 58.

[10] Baker, C.; Pradhan, A.; Pakstis, L.; Pochan, D.; Shah, S. J.Nanosci Nanotechnol. 2005, 5, 244.

[11] Tjong, S.C.; Bao, S.; e-Polymers 2007, no. 139.

[12] Ciobanu, C.; Stoica, E.; Cascaval, C. N.; Rosu, D., Rosu, L.; State, M.; Emandi, A.; Nemes, I.; Petrescu, F. Journal of Applied Polymer Science 2007, 103, 659.

[13] Ciobanu, C.; Ignat, L.; Stoica, E.; Hagiu, B.; Ciobanu, L.C. Silver plasmon influence upon biopolyurethane structure, Academy Days, lasi 26 - 28 September 2007

[14] McKiernan, R.L.; Heintz, A.M.; Hsu, S.L.; Atkins, E.D.T.; Penelle, J.; Gido, S.P. Macromolecules 2002, 35, 6970.

[15] Wang, H.; Aubuchon, S.R.; Thompson, D.G.; Osborn, J.C.; Marsh, A.L., Nichols, W.R.; Schoonover, J.R.; Palmer, R.A. Macromolecules 2002, 35, 8794.

[16] Ren, Z.; Ma, D.; Yang, X. Polymer 2003, 44, 6419.

[17] Wang, H.; Qiao, X.; Chen, J.; Wang, X.; Ding, S. Materials Chemistry and Physics 2005, 94, 449.

[18] Young, T. An essay on the cohesion of fluids, Philosophical Transactions of the Royal Society 1805, 95, 65.

[19] Fowkes, F.M. Ind. Eng. Chem. 1964, 56, 40.

[20] www.ksvltd.com/content/index/keyst

[21] Marin, J.Testing of Polymers, Interscience Publishers, vol. I, 1965.

[22] Ciobanu, C. The Polyurethane for Synthetic Lather, PhD Thesis, „Petru Poni” Institute of Macromolecular Chemistry, laşi, Romania , 1978.

[23] Ciobanu, C.; Ionescu, C.R.; Gavriliu, Ş.; Stoica, E.; Țura, V. New Methods of Synthesis Silver Nanoparticles, Meeting 23-24 May 2006, „Petru Poni” Institute of Macromolecular Chemistry, Iaşi, Romania.

[24] Melning, V.; Apostu, O.M.; Tura, V.; Ciobanu, C. Journal of Membrane Science 2005, 267, 58. 